\title{
Efeito do esterco de galinha poedeira na produção de milho e qualidade da silagem
}

\author{
Silvane de Almeida Campos ${ }^{2 *}$, Rogério de Paula Lana ${ }^{3}$, João Carlos Cardoso Galvão², \\ Mauricio Novaes Souza ${ }^{4}$, Valdir Botega Tavares ${ }^{5}$
}

10.1590/0034-737X201764030008

\section{RESUMO}

Este trabalho objetivou avaliar a influência de doses de esterco de galinha poedeira, aplicadas em cobertura, na produção de milho e na qualidade da silagem. Utilizou-se a variedade UFVM-100 Nativo. O delineamento experimental foi de blocos casualizados, com seis tratamentos $\left(0,00 ; 0,75 ; 1,50 ; 2,25 ; 3,00\right.$ e $3,75 \mathrm{t} \mathrm{ha}^{-1}$ de esterco curtido) e quatro repetições. As variáveis analisadas foram altura de planta e altura de espiga, diâmetro do colmo, prolificidade, peso de espiga, proporção de espigas na matéria verde e produtividade de matéria verde e seca de plantas. O material cortado foi ensilado e, após 64 dias de armazenamento, os silos foram abertos para determinação dos teores de matéria seca e de proteína bruta, perdas por gases e por efluente, perda de matéria seca total e recuperação de matéria seca das silagens. Os dados foram submetidos à análise de variância pelo teste $\mathrm{Fe}$, as médias, submetidas à análise de regressão. Verificouse incremento linear das produtividades das matérias verde e seca de plantas de milho, em resposta à aplicação do esterco. Para as demais características agronômicas e características avaliativas da silagem, não se verificou diferença significativa entre os tratamentos. Recomenda-se a aplicação de 3,75 t ha-1 do esterco de poedeira, para alcance de maior produção de matéria verde e seca de plantas de milho para silagem. A adubação orgânica com esterco de galinha poedeira não afetou a qualidade das silagens produzidas.

Palavras-chave: adubação; resíduo orgânico; produtividade; parâmetros qualitativos; Zea mays L.

\section{ABSTRACT}

\section{Egg-laying hen manure in the corn yield and silage quality}

The aim of this study was to measure the influence of egg-laying hen manure, used in different rates, as topdressing fertilizer on corn yield and silage quality. The corn, variety UFVM-100 Nativo, was used. The experiment consisted of a randomized block design with six treatments $\left(0.00,0.75,1.50,2.25,3.00\right.$, and $3.75 \mathrm{tha}^{-1}$ of tanned manure) and four replications. We measured the plant height, point of ear insertion, stem diameter, prolificacy, ear weight, proportion of ears in green matter, and the productivity of green and dry biomass of plants. After the harvest, the material was ensiled. After 64 days of storage, the silos were opened to determine the dry biomass, crude protein, losses by gases and by effluent, loss of total dry biomass, and dry biomass recovery of silages. Data were subjected to analysis of variance by the $\mathrm{F}$ test and the means analyzed through regression analysis. There was a linear increase in productivity of green and dry biomass of corn plants in response to manure application. The other agronomic characteristics and quality of silage did not show significant difference among treatments. The application of $3.75 \mathrm{t} \mathrm{ha}^{-1}$ hen manure is recommended to reach higher production of green and dry biomass of corn plants for silage. The organic fertilization with hen manure does not affect quality of the produced silage.

Key words: fertilization; organic waste; qualitative parameters; yield; Zea mays L.

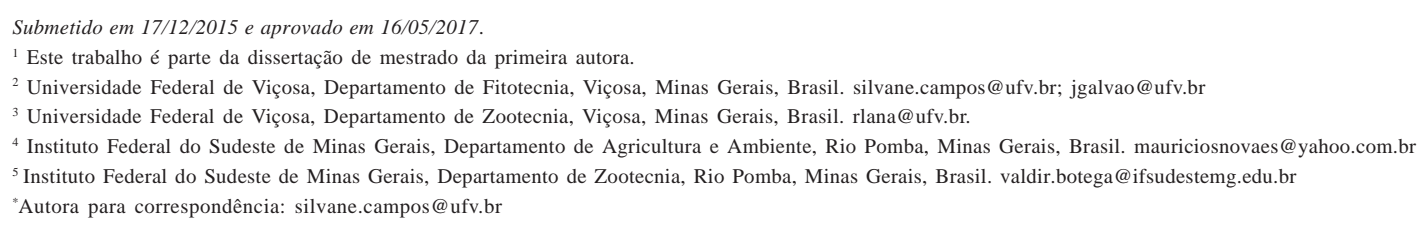




\section{INTRODUÇÃO}

O Brasil, em 2013, atingiu a condição de sétimo produtor mundial de ovos, tendo, como maiores estados produtores, São Paulo, Minas Gerais, Espírito Santo, Mato Grosso, Pernambuco, Paraná, Ceará e Goiás (Ubabef, 2014). Concomitantemente ao aumento da produção de ovos, há acréscimo do volume de esterco gerado por criadores de galinhas poedeiras (Figueroa et al., 2012). Em junho de 2015 (IBGE, 2015), estimava-se que 410.616 toneladas de esterco de poedeira foram produzidas no país. A disponibilidade desse esterco acentuou-se após a proibição do seu uso na composição da alimentação bovina em confinamento (Fernandes et al., 2013).

O esterco de galinha poedeira destaca-se dos outros em conteúdo de nutrientes, em especial, o nitrogênio, pois provém de aves alimentadas com rações concentradas (Figueroa, 2008). Com isso, as quantidades de minerais, sobretudo cálcio e fósforo, são superiores às fornecidas para frangos de corte, resultando esterco mais concentrado que o da cama aviária (Fukayama, 2008).

Esse esterco é importante fonte de matéria orgânica para o solo (Fernandes et al., 2013) e apresenta baixa relação carbono/nitrogênio (Santos et al., 2010), o que favorece a disponibilização da maior parte dos nutrientes aplicados para plantas, principalmente do nitrogênio. Essa característica, associada ao baixo preço e à alta oferta do esterco de poedeiras, tem motivado o seu uso como fertilizante e, sobretudo, fonte de nitrogênio para as plantas. $\mathrm{O}$ nitrogênio é um dos nutrientes absorvidos em maior quantidade pela cultura do milho e desempenha papel importante para o alcance de altas produtividades (Lourente $e t$ al., 2007).

A aplicação de adubos orgânicos de origem animal, desde que disponíveis, é uma alternativa para o desenvolvimento e crescimento das culturas exploradas pelos produtores rurais, em função de seus benefícios para a melhoria da fertilidade, a conservação do solo e o melhor aproveitamento dos recursos existentes na propriedade (Santos et al., 2009) ou região. No entanto, os fertilizantes orgânicos devem ser adicionados ao solo de forma a atender os critérios econômicos e conservar a sua fertilidade, mantendo ou elevando a produtividade do solo, sem menosprezar os impactos ambientais negativos que níveis elevados podem ocasionar (Silva et al., 2011). Assim, torna-se uma necessidade, à qualidade do ambiente, o descarte do resíduo da produção de ovos de forma correta (Silva et al., 2013), com uso de doses adequadas, que maximizem o potencial fertilizante e reduzam o potencial poluente.

O manejo da adubação para a cultura do milho, com vistas à produção de silagem, requer cuidados, pois a qualidade final da silagem está diretamente relacionada com o estado nutricional das plantas e com o adequado proces- so fermentativo (Basi et al., 2011). A oferta de silagem de alta qualidade pode reduzir o uso de concentrados e, por consequência, os custos de alimentação do rebanho, aumentando o lucro do produtor (Pereira et al., 2012), uma vez que a alimentação é responsável pela maior parte dos custos de produção (Pereira et al., 2007).

Assim, objetivou-se, com este trabalho, avaliar a influência de doses de esterco de galinha poedeira, aplicadas em cobertura, na produção de milho e na qualidade da silagem.

\section{MATERIAL E MÉTODOS}

O trabalho foi desenvolvido de outubro de 2013 a abril de 2014, na Estação Experimental São João, pertencente à Universidade Federal de Viçosa, situada em Coimbra, MG, com localização geográfica de 2049’37"S e $42^{\circ} 45^{\prime} 58^{\prime \prime O}$ e $719 \mathrm{~m}$ de altitude. A área se caracteriza, climaticamente, por temperatura média anual de $19^{\circ} \mathrm{C}$ e precipitação média anual de 1.300 a 1.400 mm, concentrada, principalmente, de outubro a março. Na Figura 1, estão apresentados os dados climáticos registrados no município de Viçosa, MG, no decorrer do experimento. Este município tem altitude de $648 \mathrm{~m}$ e situa-se a $20 \mathrm{~km}$ de Coimbra, MG, onde se realizou a pesquisa, apresentando aspectos climáticos semelhantes.

O solo da área experimental é classificado como Argissolo Vermelho-Amarelo Câmbico, fase terraço (Embrapa, 2013), muito argiloso. Nesta área, por muito tempo, cultivou-se o milho para produção de grãos, no verão, e o feijão, no inverno, ambos submetidos ao manejo convencional. Assim, realizou-se o cultivo do milho no ano agrícola 2012-2013 e, após a colheita, os restos culturais permaneceram na superfície do solo. Os resultados da análise do solo, na camada de 0-0,20 m, indicaram: $\mathrm{pH}$ (água) 5,3; P e K 21,8 e $66 \mathrm{mg} / \mathrm{dm}^{3}$, respectivamente, $\mathrm{Ca}^{2+}, \mathrm{Mg}^{2+}$, $\mathrm{Al}^{3+}, \mathrm{H}+\mathrm{Al}, \mathrm{SB}, \mathrm{CTC}(\mathrm{t})$ e CTC(T) 1,$9 ; 1,0 ; 0,1 ; 4,46 ; 3,07$; 3,17 e $7,53 \mathrm{cmolc} \mathrm{dm}^{-3}$, respectivamente, $\mathrm{V} 41 \%$ e m de $3 \%$.

Efetuou-se a calagem com base nos resultados da análise química do solo. Os restos culturais deixados na superfície foram incorporados, durante o preparo da área, com uma aração, seguida de uma gradagem leve, por ocasião da implantação da cultura.

O esterco proveio de galinhas da raça $\mathrm{H}$-line, alimentadas com ração. Após ter permanecido no Aviário da própria Instituição entre 12 e 18 meses, foi retirado para compostagem, que apresentou a seguinte composição química na matéria seca: $\mathrm{N}$ (método do Kjeldahl), P, K, Ca, $\mathrm{Mg}$ e S - 1,08; 2,25; 2,32; 17,22; 0,68 e 0,87\%, respectivamente; Zn, Fe, Mn, Cu e B - 730; 18; 658; 106 e 43,6 ppm; $\mathrm{CO} 6,24 \%$; C/N 5,77; pH (água) 7,38 e umidade de 27,36\%.

Conduziu-se o experimento em blocos casualizados, com seis tratamentos e quatro repetições. Os tratamentos 
consistiram nas doses em base úmida: 0,00 - sem esterco; 0,$75 ; 1,50 ; 2,25 ; 3,00$ e $3,75 \mathrm{t} \mathrm{ha}^{-1}$ de esterco curtido, em parcelas constituídas por $20 \mathrm{~m}^{2}$.

No dia 16/10/2013, efetuou-se a semeadura do milho, variedade UFVM-100 Nativo, com semeadora mecanizada de três linhas, com espaçamento de $0,80 \mathrm{~m}$, depositandose seis sementes $\mathrm{m}^{-1}$, visando à população de 60.000 plantas ha- ${ }^{-1}$.

A adubação de cobertura realizou-se quando a cultura atingiu o estádio fenológico V2 (duas folhas totalmente desenvolvidas), sendo o esterco aplicado e incorporado ao lado da linha de plantio. Fez-se o controle de plantas espontâneas e da lagarta do cartucho (Spodoptera frugiperda) com pulverização de óleo de nin (Azadirachta indica $)(100 \mathrm{~mL})$, diluído em água $(20 \mathrm{~L})$. A cultura recebeu irrigação na fase vegetativa, quando necessário.

No momento da colheita (estádio grão farináceo), em 28/01/2014, dez plantas da área útil foram avaliadas quanto à altura de planta $(\mathrm{m})$, altura de espiga $(\mathrm{m})$, diâmetro de colmo (mm), prolificidade, peso de espiga $(\mathrm{g})$ e proporção de espigas na matéria verde (dividiu-se a produtividade de espigas pela produtividade de matéria verde de plantas) expressa em percentagem. Calculou-se a produtividade de espigas $\left(\mathrm{kg} \mathrm{ha}^{-1}\right)$, multiplicando a prolificidade obtida pela população de plantas utilizada, sendo o resultado multiplicado pelo peso de espigas em $\mathrm{kg}$. As espigas foram colhidas manualmente. Após as avaliações, as plantas foram cortadas a $15 \mathrm{~cm}$ da superfície do solo, trituradas em ensiladeira estacionária, sendo o material armazenado e adequadamente compactado em tubos de PVC $(10 \mathrm{~cm}$ de diâmetro x $50 \mathrm{~cm}$ de altura). Os tubos continham areia seca $(1,2 \mathrm{~kg})$ no fundo para a recuperação do efluente, foram vedados com tampas providas de válvula tipo Bunsen, para permitir o escoamento de gases, e lacrados com fita adesiva, para evitar a troca de ar com o meio.

Aos 64 dias após a ensilagem do material, em 03/04/ 2014, foram coletadas sub-amostras, que foram secadas em estufa, a $60^{\circ} \mathrm{C}$, por 72 horas, para obtenção do teor de matéria seca das silagens e posterior análise do teor de nitrogênio total. A concentração de proteína bruta foi obtida, multiplicando-se o teor de nitrogênio total pelo fator de conversão 6,25 (Galvani \& Gaertner, 2006).

As perdas de MS nas silagens, sob as formas de gases e efluente, foram quantificadas por diferença de peso. As perdas por gases (PG) foram estimadas de acordo com a fórmula:

$$
P G(\% M S)=\frac{P b c h f-P b c h a}{M v f o x M S f o} \times 1000
$$

(Jobim et al., 2007), em que Pbchf é o peso do balde cheio no fechamento $(\mathrm{kg})$, Pbcha é o peso do balde cheio na abertura (kg), MVfo é a massa verde de forragem no fechamento (kg) e MSfo é a MS da forragem no fechamento (\%), com base na diferença de peso da massa de forragem seca. Calcularam-se as perdas por efluente (PE) pela equação:

$$
P E(k g / t M V)=\frac{P e f x 1000}{M v i}
$$

(Jobim et al., 2007), em que Pef é o peso do efluente (peso do conjunto vazio após a abertura - peso do conjunto vazio antes do enchimento) ( $\mathrm{kg}$ ), MVi é a quantidade de massa verde de forragem ensilada $(\mathrm{kg})$. $\mathrm{O}$ peso do conjunto corresponde à massa do balde + tampa + areia + tecido. Calculou-se a perda por efluente em $\%$ da MS, dividindose a produção de efluente em $\mathrm{kg} / \mathrm{t}$ MV pelo \% MS/100, cujo resultado foi dividido pelo volume do silo (L).

A determinação das perdas de matéria seca totais (PMST) foi calculada pela diferença entre os pesos brutos de MS inicial e final dos silos, em relação à quantidade de forragem ensilada (MS), pela fórmula:

$P M S T(\% M S)=\frac{M s i-M S f}{M s i} \times 100$

(Schmidt, 2006), em que MSi é a quantidade de MS inicial (peso do silo após enchimento - peso do conjunto vazio antes do enchimento), multiplicada pelo teor de MS da forragem na ensilagem; MSf é a quantidade de MS final (peso do silo cheio antes da abertura - peso do conjunto vazio após a abertura dos silos), multiplicada pelo teor de MS da forragem na abertura. A recuperação de matéria seca (RMS) da silagem foi estimada pela equação:

$R M S(\% M S)=\frac{M f a b \times M S a b}{\text { Mffe } \times \text { MSfe }} \times 100$

(Jobim et al., 2007), em que MFab é a massa de forragem na abertura (kg), MSab é o teor de MS (\%) na abertura, MFfe é a massa de forragem no fechamento (kg) e MSfe é o teor de MS (\%) da forragem no fechamento.

Para verificar o efeito dos níveis de adubação sobre as variáveis analisadas, os dados experimentais foram submetidos à análise de variância e regressão $(\mathrm{p}<0,05)$ por meio do software ASSISTAT versão 7.7 beta (Silva \& Azevedo, 2009).

\section{RESULTADOS E DISCUSSÃO}

As variáveis altura de planta (AP), altura de espiga (AE), diâmetro do colmo (DC), prolificidade (PROL), peso de espiga (PEE) e proporção de espigas na matéria verde (PRE) de plantas de milho não apresentaram diferenças significativas em função das doses de esterco (Tabela 1).

Registrou-se média de 2,1 m para a AP (Tabela 1), que se encontra de acordo com a altura de planta desse cultivar, que varia de 2,00 a 2,30 m. Vieira et al. (2014) notaram que a AP da variedade de milho BRS Gorutuba também não foi influenciada pelo aumento de doses de composto orgânico. Já Silva et al. (2013) verificaram que essa variá- 
vel foi favorecida pela adição de doses de cama de poedeiras.

Para a AE, constatou-se média de 1,2 m (Tabela 1), pouco acima da altura de espiga da variedade utilizada, que varia de 1,00 a 1,15 m. Vieira et al. (2014) perceberam que a adição de doses crescentes de composto orgânico também não afetou a AE dessa variedade. Farinelli \& Lemos (2010) verificaram que a AE de milho híbrido não foi afetada pelas doses crescentes de nitrogênio (ureia) em cobertura.

O DC apresentou média de 20,7 mm (Tabela 1), dentro da normalidade para o milho, que varia de 20-22 mm. O DC é característica de grande importância, pois plantas com maior diâmetro basal são menos propensas a tombamento e quebramento, facilitando a colheita. Carmo et al. (2012) constataram que, para as mesmas doses, independentemente da fonte nitrogenada aplicada em cobertura, verificou-se resposta linear do DC de milho doce.

Os resultados encontrados para AP, AE e DC de milho são atribuídos às condições edafoclimáticas favoráveis durante a fase vegetativa da cultura, à adequada população de plantas e às características de rusticidade, elevada tolerância à acidez do solo, eficiência no uso do nitrogênio e boa capacidade produtiva do cultivar utilizado. As parcelas em que se aplicaram as menores doses de esterco produziram semelhantemente às parcelas com maior dose, em função das condições do solo.

APROL média obtida foi de 1,0 (Tabela 1). Farhad et al. (2009) também verificaram que a PROL não foi afetada significativamente pela aplicação de diferentes níveis de esterco de galinha. Similarmente, Cruz et al. (2010) averiguaram que a adubação com esterco aviário não influenciou a prolificidade de milho forragem. Em se tratando de variedade de milho, o estande de 60 mil é considerado alto. Os resultados evidenciam a capacidade produtiva da variedade, em razão de a PROL atingir, em média, valores de 1,0. Na cultura de milho com população acima da ideal, há ocorrência de plantas sem espiga, efeito não encontrado nesta pesquisa, mostrando a capacidade adaptativa do cultivar a altas populações. Na finalidade silagem, a participação das espigas é fundamental para a qualidade nutricional, sendo especialmente dependente também do estande final de plantas.

Obteve-se PEE de milho de $204 \mathrm{~g}$ (Tabela 1), inferior ao peso médio de espiga da variedade utilizada, que é de 250 g. Cancellier et al. (2010) também não detectaram efeito significativo para o PEE de milho variedade, em relação à aplicação de doses de esterco bovino curtido, no sulco de plantio. Já Santos et al. (2009) notaram que a adubação com cama de galinha caipira aumentou o PEE da cultura do milho. O menor PEE verificado nesta pesquisa, o que não é desejável, pode ser atribuído à reduzida translocação de nutrientes para o enchimento de grãos, causada pelo longo veranico no período reprodutivo entre o florescimento (25/12/2013) e a colheita (28/01/2014) (Figura 1). O desempenho animal melhora com o aumento do conteúdo de grãos na forragem, pois estes, além de contribuírem para a elevação da qualidade da silagem, em virtude do melhor valor nutritivo, têm maior participação na percentagem de MS da massa ensilada, favorecendo, a melhor fermentação dentro do silo.

Detectou-se valor médio de 33\% para a PRE da planta de milho (Tabela 1). A baixa PRE encontrada deve-se ao menor PEE produzido, que refletiu-se em menor produtividade de espigas. Ressalta-se que, quanto maior a quantidade de espigas na forragem, maior será a presença de grãos. No grão está a maior concentração de amido e de açúcares solúveis. Desta forma, é desejável maior PRE no material a ser ensilado, pois quanto maior a proporção de grãos presentes, melhor será a qualidade fermentativa e nutricional da silagem. A matéria- prima para ensilagem deve ter, em sua composição, aproximadamente, de 40 a $50 \%$ de grãos na MS da planta. Quanto maior for esta proporção, melhor a fermentação no silo, propiciando silagens de maiores valor energético, digestibilidade aparente, consumo e conversão alimentar.

Observou-se efeito linear das doses de esterco de galinha poedeira sobre a produtividade de matéria verde (PMV) (Figura 2). O maior incremento de PMV foi de 45.578 $\mathrm{kg} \mathrm{ha}^{-1}$, constatado pela adição de $3,75 \mathrm{t} \mathrm{ha}^{-1}$ do esterco,

Tabela 1: Resumo da análise de variância para altura de planta (AP) e de espiga (AE), diâmetro do colmo (DC), prolificidade (PROL), peso de espiga (PEE) e proporção de espigas (PRE), na matéria verde de plantas de milho variedade UFVM-100 Nativo, adubado com doses de esterco de galinha poedeira. Coimbra, MG, 2014

\begin{tabular}{lccccccc}
\hline \multirow{2}{*}{ FV } & \multicolumn{7}{c}{ Quadrado Médio } \\
\cline { 2 - 8 } & $\mathbf{G L}$ & $\mathbf{A P}$ & $\mathbf{A E}$ & $\mathbf{D C}$ & PROL & PEE & PRE \\
\hline Tratamentos & 5 & $0,0236^{\mathrm{ns}}$ & $0,0155^{\mathrm{ns}}$ & $2,9781^{\mathrm{ns}}$ & $0,0026^{\text {ns }}$ & $0,0317^{\mathrm{ns}}$ & $0,0106^{\mathrm{ns}}$ \\
Blocos & 3 & $0,0335^{\mathrm{ns}}$ & $0,0176^{\mathrm{ns}}$ & $12,4107^{\mathrm{ns}}$ & $0,0005^{\mathrm{ns}}$ & $0,0741^{\text {ns }}$ & $0,0125^{\mathrm{ns}}$ \\
Resíduo & 15 & $0,0331^{\mathrm{ns}}$ & 0,0162 & 2,8063 & 0,0028 & 0,0103 & 0,0051 \\
\hline Total & 23 & - & - & - & - & - & - \\
\hline CV $(\%)$ & & 8,28 & 10,34 & 8,08 & 8,14 & 17,45 & 19,09 \\
\hline
\end{tabular}

ns - F não significativo a 5\%; FV - Fonte de Variação; CV - Coeficiente de variação. 
com acréscimo de $33 \%$ em comparação ao do controle. Silva et al. (2013) verificaram que o aumento das doses de esterco de poedeira proporcionou incremento da PMV do capim Brachiaria brizantha cv. Marandu, obtendo-se os melhores resultados com $15 \mathrm{t} \mathrm{ha}^{-1}$. A PMV é uma das primeiras características a se avaliar, quando se busca informação sobre determinado cultivar para produção de silagem. Contribui com a diluição dos custos de implantação da cultura, por elevar a produtividade. Quanto maior a produtividade, menor será o custo de cada tonelada produzida. A maior produtividade verificada nesta pesquisa revela o potencial de uso de esterco de poedeira na fertilização da variedade de milho destinada à silagem, com maior expectativa de diluição de custos da cultura em propriedades familiares.

A produtividade de matéria seca (PMS) foi influenciada pelo aumento das doses de esterco de galinha poedeira (Figura 3). A dose de 3,75 t ha-1 do esterco propiciou maior produtividade, alcançando-se $15.285 \mathrm{~kg} \mathrm{ha}^{-1}$, superando a do controle em 43\%. Vieira et al. (2014) verificaram que a PMS da variedade de milho foi significativamente afetada pelas doses de composto orgânico adicionadas, ajustando-se a equação linear crescente. Já Cesarino (2006) percebeu que a PMS da variedade de milho AL-Bandeirante para ensilagem não foi influenciada pelo aumento das doses de dejeto líquido de suíno fermentado, quando aplicadas em cobertura.

Os PMV e PMS verificados devem-se às condições dos solos do experimento e à adição de adubação orgânica. Os resultados podem ser justificados em função de rápida mineralização de nutrientes presentes no esterco, em decorrência da baixa relação $\mathrm{C} / \mathrm{N}$, elevando a fertilidade do solo cultivado. Provavelmente, ocorreu sincronismo entre a liberação dos nutrientes e a época de maior exigência da variedade empregada, a qual apresenta alta capacidade de produção. A irrigação realizada durante a fase vegetativa da cultura, quando necessário; o manejo de plantas espontâneas e o controle da lagarta do cartucho

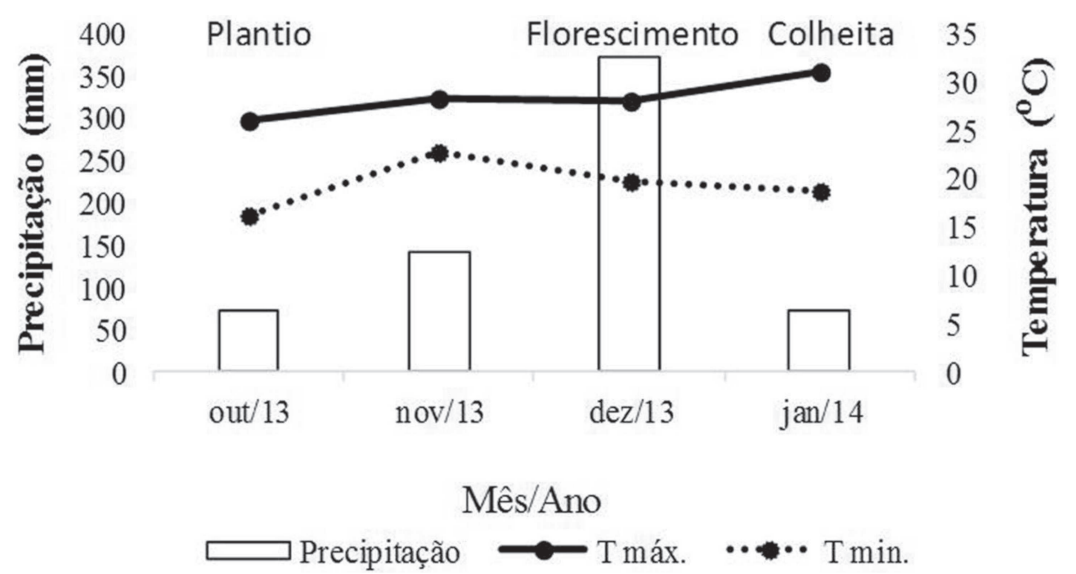

Figura 1: Dados da precipitação pluviométrica $(\mathrm{mm})$ e das temperaturas máxima e mínima $\left({ }^{\circ} \mathrm{C}\right)$, registrados no município de Viçosa, MG, no decorrer do experimento. Viçosa, MG, 2013-2014.

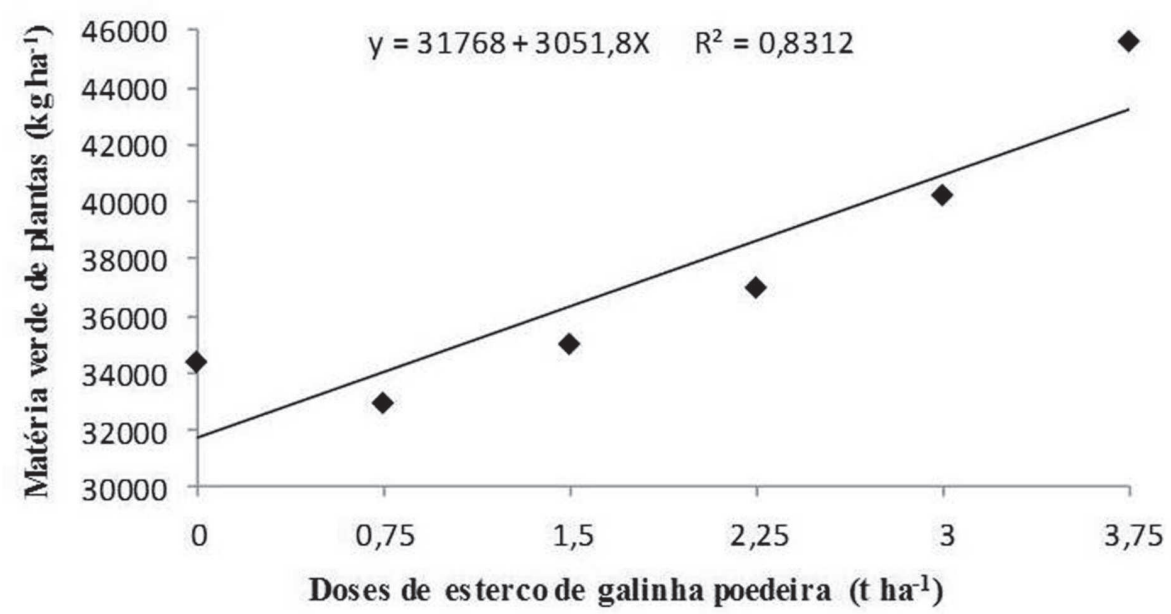

Figura 2: Produtividade de matéria verde de plantas de milho variedade UFVM-100 Nativo, em resposta à aplicação de doses de esterco de galinha poedeira. Coimbra, MG, 2014. 
também colaboraram para o alcance dessas produtividades.

Com relação aos parâmetros qualitativos da silagem, o esterco de galinha poedeira não afetou os teores de matéria seca (MS) e de proteína bruta (PB), as perdas gasosas (PG) e por efluente (PE), as perda de matéria seca total (PMST) e a recuperação de matéria seca (RMS) das silagens produzidas (Tabela 2 ).

Determinou-se o teor médio de MS das silagens, de $30,72 \%$ (Tabela 2). O teor de MS da planta forrageira determina o tipo de fermentação que irá se desenvolver no interior do silo (Schena et al., 2007). As plantas de milho foram colhidas no estádio adequado à ensilagem, com teor médio de $32,11 \%$ de MS, fato que contribuiu para que o teor de MS verificado nas silagens estivesse dentro do padrão de fermentação de boa qualidade. A massa de grãos detém a maior contribuição para o percentual de MS da massa ensilada. Além disso, segundo França et al. (2011), a produção de efluente, consequentemente, eleva os teores de MS do material ensilado. O conhecimento do teor de MS contida na silagem é importante, pois com base nele se estabelece o cálculo da dieta, já que o consumo de alimento pelos animais é estabelecido em $\mathrm{kg}$ de MS/animal/dia.
França et al. (2011) verificaram que o conteúdo de MS das silagens dos híbridos 1F 305 e 0369267 de sorgo diferiram em função das doses de nitrogênio (sulfato de amônio) aplicadas.

Registrou-se teor médio de 5,11\% da MS de PB das silagens avaliadas (Tabela 2). Cesarino (2006) também verificou que o teor de $\mathrm{PB}$ de silagens de milho variedade AL-Bandeirante não foi afetado pelas doses de dejeto líquido de suíno fermentado, aplicadas em cobertura. Macedo et al. (2012) notaram que o teor de PB das silagens de sorgo não diferiu entre os níveis de sulfato de amônio adicionados em cobertura. O teor de PB obtido nesta pesquisa está aquém de valores normalmente encontrados para silagem de milho, pois apresenta teores moderados de PB, entre 6 e $9 \%$. O baixo teor de PB deve-se ao menor conteúdo de $\mathrm{N}$ total presente nas subamostras (média de $0,817 \mathrm{dag} / \mathrm{kg}$ ) das silagens de cada parcela. O esterco utilizado no experimento apresentou $1,08 \%$ de N, provavelmente, em decorrência das perdas desse nutriente por volatilização de amônia, em razão do seu tempo de permanência no aviário, fato que pode ter contribuído para esse resultado. Outra possível justificativa para a redução da percentagem de PB pode ser atribuída ao aumento da PMS,

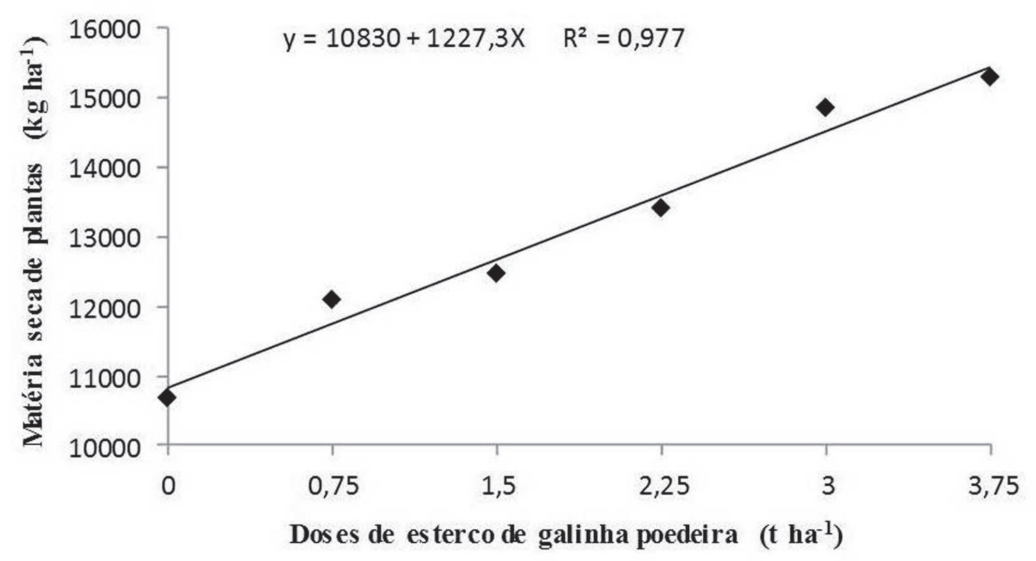

Figura 3: Produtividade de matéria seca de plantas de milho variedade UFVM-100 Nativo, em resposta à aplicação de doses de esterco de galinha poedeira. Coimbra, MG, 2014.

Tabela 2: Resumo da análise de variância dos teores de matéria seca (MS) e de proteína bruta (PB), perdas por gases e efluente, perda de matéria seca total (PMST) e recuperação de matéria seca (RMS) das silagens da planta de milho variedade UFVM-100 Nativo, fertilizado com doses de esterco de galinha poedeira. Coimbra, MG, 2014

\begin{tabular}{lcccccccc}
\hline & \multicolumn{7}{c}{ Quadrado Médio } \\
\cline { 2 - 9 } FV & $\mathbf{G L}$ & $\begin{array}{c}\text { MS } \\
(\boldsymbol{\%})\end{array}$ & $\begin{array}{c}\text { PB } \\
(\boldsymbol{\%} \mathbf{M S})\end{array}$ & $\begin{array}{c}\text { Gases } \\
(\boldsymbol{\%} \mathbf{M S})\end{array}$ & $\begin{array}{c}\text { Efluente } \\
(\mathbf{k g} / \mathbf{t M V})\end{array}$ & $\begin{array}{c}\text { Efluente } \\
(\boldsymbol{\%} \mathbf{M S})\end{array}$ & $\begin{array}{c}\text { PMST } \\
(\boldsymbol{\%} \mathbf{M S})\end{array}$ & $\begin{array}{c}\text { RMS } \\
(\boldsymbol{\%})\end{array}$ \\
\hline Tratamentos & 5 & $4,0990^{\text {ns }}$ & $0,0136^{\text {ns }}$ & $0,0078^{\text {ns }}$ & $6,2227^{\text {ns }}$ & $0,0333^{\text {ns }}$ & $11,1759^{\text {ns }}$ & $11,1759^{\text {ns }}$ \\
Blocos & 3 & $3,4861^{\text {ns }}$ & $0,0053^{\text {ns }}$ & $0,0047^{\text {ns }}$ & $5,2039^{\text {ns }}$ & $0,5163^{\text {ns }}$ & $14,9246^{\text {ns }}$ & $14,9246^{\text {ns }}$ \\
Resíduo & 15 & $5,4767^{\text {ns }}$ & 0,0126 & 0,0027 & 9,8649 & 1,5678 & 33,2562 & $33,2562^{\text {ns }}$ \\
\hline Total & 23 & - & - & - & - & - & - & - \\
\hline CV $(\%)$ & & 7,62 & 2,20 & 14,49 & 15,85 & 15,75 & 13,70 & 6,32 \\
\hline
\end{tabular}

MS - matéria seca; MV - matéria verde; ${ }^{\text {ns }}$ - F não significativo a 5\%; FV - Fonte de Variação; CV - Coeficiente de variação. 
que causa diluição da proteína na MS (Vilela et al., 2008) e também à baixa PRE (33\%), uma vez que os teores foram semelhantes entre os tratamentos, em decorrência do longo veranico no período reprodutivo entre o florescimento e a colheita, que resultou em menores peso e produtividade de espigas. Observa-se que as silagens produzidas não atenderiam satisfatoriamente aos requisitos proteicos mínimos dos ruminantes (7\%), sendo vantajosa a complementação do teor proteico, pois conforme Basi et al. (2011), silagens de maior valor nutricional tendem a melhorar o consumo e o desempenho dos animais.

Quantificaram-se baixas PG na fermentação das silagens, com média de $0,37 \%$ da MS (Tabela 2). Neste estudo, as PG foram relativamente menores que as PE. A formação de gás na silagem é resultante de fermentação secundária exercida por enterobactérias, bactérias Clostridium e micro-organismos aeróbicos, que, normalmente, crescem em meios com pH mais elevado (Amaral et al., 2007). A redução das PG deve-se, provavelmente, à redução da ação desses micro-organismos produtores de gás, que se desenvolvem em silagens afetadas por má fermentação (Edvan et al., 2013), decorrente da transformação das proteínas e carboidratos por micro-organismos que geram vários produtos, como ácidos orgânicos, etanol, água, ATP e $\mathrm{CO}_{2}$ (Siqueira, 2005). Rigueira et al. (2013) também não observaram efeito da adubação com níveis de sulfato de amônio sobre a produção de gás das silagens de Panicum maximum cv. Mombaça e de Brachiaria decumbens $\mathrm{cv}$. Basilisk avaliadas.

$\mathrm{O}$ valor médio obtido para a PE das silagens foi de $19,01 \mathrm{~kg} / \mathrm{t}$ de massa verde, ou 6,18\% da MS (Tabela 2). Rigueira et al. (2013) notaram que a adubação nitrogenada com sulfato de amônio aumentou as PE do Panicum maximum cv. Mombaça, encontrando maiores $\mathrm{PE}$, quando a cultura desse capim foi fertilizada com $60 \mathrm{~kg} \mathrm{de} \mathrm{N} \mathrm{ha}^{-1}$. Oliveira (2005) verificou aumento da produção de efluentes das silagens de sorgo forrageiro, para o híbrido 0369255 , de acordo com a elevação do N (sulfato de amônio) aplicado em cobertura. A PE é elevada em silagens com teor de MS inferior a 30\% (Silva et al., 2011), o que não foi verificado nesta pesquisa. As pequenas perdas de MS por efluentes, possivelmente, devem-se ao adequado processo de ensilagem do material original, que é influenciado, sobretudo, pelo teor de MS, pelo processamento físico da forragem, pelo tipo de silo e pelo grau de compactação (França et al., 2011). As silagens produzidas com milho no estádio $1 / 2$ e 2/3 da linha do leite, por sua vez, estiveram dentro da faixa ideal preconizada na literatura, entre 30 a $35 \%$, para que ocorra boa fermentação da massa ensilada, garantindo condições para a obtenção de silagens de boa qualidade. Com esses valores de MS, a atividade clostrídica é reduzida ou lenta, permitindo a proliferação de bactérias produtoras de ácido lático e acético.
Quanto à PMST, constatou-se média de 8,82\% (Tabela 2). Os teores de MS da silagem foram, em média, 1,39\% inferiores aos teores da forragem original, o que é normal, considerando-se as perdas ocorridas durante o processo de fermentação, as quais ocorrem em média de $10 \%$. Assim, em relação ao teor de MS, as perdas foram pequenas, indicando boas condições de conservação. A PMST está relacionada com as PE, em relação às baixas PG. Segundo Muck (2010), as menores perdas em silagem de milho podem ser atribuídas ao teor adequado de MS e de carboidratos solúveis e ao baixo poder tampão, permitindo rápida e adequada fermentação lática, declínio do pH e conservação da silagem.

Encontrou-se média de $91,18 \%$ para a RMS das silagens (Tabela 2). Essa variável está relacionada com as perdas, ou seja, maiores perdas geram menores valores de RMS. Os valores relativamente altos de RMS podem estar correlacionados, sobretudo, com a baixa PG, ao se comparar com a PE. Os teores de MS do material original encontraram-se dentro do limite de 30 a $35 \%$, considerado ideal para que haja o favorecimento da fermentação lática adequada, visando à manutenção do valor nutritivo da silagem. Este fato, aliado à adequada compactação média da forragem, de $543 \mathrm{~kg} / \mathrm{m}^{3}$, influenciou na RMS.

\section{CONCLUSÕES}

Recomenda-se a aplicação de $3,75 \mathrm{t} \mathrm{ha}^{-1}$ do esterco de galinha poedeira para alcance de maiores produções de matérias verde e seca de plantas de milho para silagem.

A adubação orgânica com esterco de galinha poedeira não afetou a qualidade das silagens produzidas.

\section{AGRADECIMENTOS}

Os autores agradecem à CAPES e à FAPEMIG pela concessão de bolsa de mestrado à primeira autora.

\section{REFERÊNCIAS}

Amaral RC, Bernardes TF, Siqueira GR \& Reis RA (2007) Características fermentativas e químicas de silagens de capim-marandu produzidas com quatro pressões de compactação. Revista Brasileira de Zootecnia, 36:532-539.

Basi S, Neumann M, Marafon F, Ueno RK \& Sandini IE (2011) Influência da adubação nitrogenada sobre a qualidade da silagem de milho. Pesquisa Aplicada \& Agrotecnologia, 4:219-234.

Cancellier LL, Afférri FS, Adorian GC \& Rodrigues HVM (2010) Influencia da adubação orgânica na linha de semeadura na emergência e produção forrageira de milho. Revista Verde de Agroecologia e Desenvolvimento Sustentável, 5:25-32.

Carmo MS, Cruz SCS, Souza EJ, Campos LFC \& Machado CG (2012) Doses e fontes de nitrogênio no desenvolvimento e produtividade da cultura de milho doce (Zea mays convar. Saccharata var. Rugosa). Bioscience Journal, 28:223-231.

Cesarino RO (2006) Milho fertirrigado com dejetos líquidos de suínos para ensilagem. Dissertação de Mestrado. Universidade José do Rosário Vellano, Alfenas. 51p. 
Cruz JC, Pereira Filho IA, Moreira JAA \& Matrangolo WJR (2010) Resposta de Cultivares de Milho à Adubação Orgânica para Consumo Verde, Grãos e Forragem em Sistema Orgânico de Produção. In: XXVIII Congresso Nacional de Milho e Sorgo, Goiânia. Anais, ABMS. p.2420-2428

Edvan RL, Carneiro MSS, Coutinho MJF, Silva EB, Oliveira GS, Silva MSM \& Albuquerque DR (2013) Perdas e composição bromatológica de silagem de gliricídia contendo diferentes níveis de vagem de algaroba. Tecnologia \& Ciência Agropecuária, 7:63-68.

Embrapa - Empresa Brasileira de Pesquisa Agropecuária (2013) Sistema brasileiro de classificação de solos. $3^{\mathrm{a}}$ ed. Brasília, Embrapa. 353p.

Farhad W, Saleem MF, Cheema MA \& Hammad HM (2009) Effect of poultry manure levels on the productivity of spring maize (Zea mays L.). The Jornal of Animals \& Plant Sciences, 19:122125

Farinelli R \& Lemos LB (2010) Produtividade e eficiência agronômica do milho em função da adubação nitrogenada e manejos do solo. Revista Brasileira de Milho e Sorgo, 9:135-146.

Fernandes ALT, Santinato F, Ferreira RT \& Santinato R (2013) Adubação orgânica do cafeeiro, com uso do esterco de galinha, em substituição à adubação mineral. Coffee Science, 8:486-499.

Figueroa EA (2008) Efeito imediato e residual de esterco de ave poedeira em culturas de grãos. Dissertação de Mestrado. Universidade de Passo Fundo, Passo Fundo. 129p.

Figueroa EA, Escosteguy PAV \& Wiethölter S (2012) Dose de esterco de ave poedeira e suprimento de nitrogênio à cultura do trigo. Revista Brasileira de Engenharia Agrícola e Ambiental, 16:714-720.

França AFS, Oliveira RP, Rodrigues JAS, Miyagi ES, Silva AG, Peron HJMC, Abreu JBR \& Bastos DC (2011) Características fermentativas da silagem de híbridos de sorgo sob doses de nitrogênio. Ciência Animal Brasileira, 12:383-391.

Fukayama EH (2008) Características quantitativas e qualitativas da cama de frango sob diferentes reutilizações: efeitos na produção de biogás e biofertilizante. Tese de Doutorado. Faculdade de Ciências Agrárias e Veterinárias do Campus de Jaboticabal, Jaboticabal. 99p.

Galvani F \& Gaertner E (2006) Adequação da metodologia Kjeldahl para determinação de nitrogênio total e proteína bruta. Corumbá, Embrapa Pantanal. 9p. (Circular Técnica, 63).

IBGE - Instituto Brasileiro de Geografia e Estatística (2015) Produção de Ovos de Galinha - julho-setembro 2015. Disponível em: <http://www.sidra.ibge.gov.br/bda/default.asp?t=4\&z=t\&o= $1 \& u 1=1 \& u 2=1 \& u 3=u=1 \& u 5=1 \& u 6=1 \& u 7=1 \& u 8=1 \& u 9=$ $1 \& u 10=1 \& u 11=1 \& u 12=3 \& u 13=1 \& u 14=26674 \& u 15=1 \& u 16=$ $1 \& u 17=1>$. Acessado em: 15 de dezembro de 2015.

Jobim CC, Nussio LG, Reis RA \& Schmidt P (2007) Avanços metodológicos na avaliação da qualidade da forragem conservada. Revista Brasileira de Zootecnia, 36:101-119.

Lourente ERP, Ontocelli R, Souza LCF, Gonçalves MC, Marchetti ME \& Rodrigues ET (2007) Culturas antecessoras, doses e fontes de nitrogênio nos componentes de produção do milho. Acta Scientiarum Agronomy, 29:55-61.

Macedo CHO, Andrade AP, Santos EM, Silva DS, Silva TC \& Edvan RL (2012) Perfil fermentativo e composição bromatológica de silagens de sorgo em função da adubação nitrogenada. Revista Brasileira de Saúde e Produção Animal, 13:371-382.

Muck RE (2010) Silage microbiology and its control through additives. Revista Brasileira de Zootecnia, 39:183-191.
Oliveira RP (2005) Caracterização agronômica, potencial produtivo e composição bromatológica da planta e da silagem de híbridos de sorgo sob doses crescentes de nitrogênio. Dissertação de Mestrado. Universidade Federal de Goiás, Goiânia. 59p.

Pereira ES, Mizubuti IY, Pinheiro SM, Villarroel ABS \& Clementino RH (2007) Avaliação da qualidade nutricional de silagens de milho (Zea mays L.). Revista Caatinga, 20:08-12.

Pereira LB, Komuro LK, Santos NCB, Souza LCD \& Aline Oliveira EZ (2012) Aplicação de Adubo em Milho Verde Orgânico Irrigado. In: XXIX Congresso Nacional de Milho e Sorgo, Águas de Lindóia. Anais, ABMS. p.1488-1493.

Rigueira JPS, Pereira OG, Ribeiro KG, Mantovani HC \& Agarussi MCN (2013) The chemical composition, fermentation profile, and microbial populations in tropical grass silages. Revista Brasileira de Zootecnia, 42:612-621.

Santos FG, Escosteguy PAV \& Rodrigues LB (2010) Qualidade de compostos de esterco de ave poedeira submetido a dois tipos de tratamento de compostagem. Revista Brasileira de Engenharia Agrícola e Ambiental, 14:1101-1108.

Santos JF, Grangeiro JIT, Oliveira MEC, Bezerra AS \& Santos MCCA (2009) Adubação orgânica na cultura do milho no Brejo Paraibano. Engenharia Ambiental, 6:209-216.

Schena TE, Silva RCCA \& Ferreira SAC (2007) Comparação de três metodologias para a determinação da matéria seca de plantas de milho (Zea mays L.) destinadas à produção de silagem. In: $16^{\circ}$ Encontro Anual de Iniciação Científica, Ponta Grossa. Anais, Universidade Estadual de Ponta Grossa. CD ROM.

Schmidt P (2006) Perdas fermentativas na ensilagem, parâmetros digestivos e desempenho de bovinos de corte alimentados com rações contendo silagens de cana-de-açúcar. Tese de Doutorado. Escola Superior de Agricultura Luiz de Queiroz, Piracicaba. 228p.

Silva FAS \& Azevedo CAV (2009) Principal Components Analysis in the Software Assistat-Statistical Atten dance. In: $7^{\text {th }}$ World Congress on Computers in Agriculture, Reno. Proceedings, American Society of Agricultural and Biological Engineers. CD ROM.

Silva PRD, Landgraf MD \& Rezende MOO (2011) Avaliação do potencial agronômico de vermicomposto produzido a partir de lodo de esgoto doméstico. Revista Brasileira de Ciências Agrárias, 6:565-571.

Silva TR, Menezes JFS, Simon GA \& Assis RL (2013) Desenvolvimento inicial do milho em um latossolo vermelho distrófico com aplicação de cama de poedeira. Global Science and Technology, 6:1-7.

Siqueira GR (2005) Cana-de-açúcar (Saccharum officinarum L.) ensilada com aditivos químicos e bacterianos. Dissertação de Mestrado. Universidade Estadual Paulista, Jaboticabal. 91p.

Ubabef - União Brasileira de Avicultura (2014) Relatório anual 2014. Disponível em: <http://abpa-br.com.br/files/publicacoes/ 8ca705e70f0cb110ae3aed67d29c8842.pdf >. Acessado em: 30 de agosto de 2014.

Vieira LV, Souza HÁ, Soares LSP \& Ziegler HRS (2014) Doses de composto orgânico proveniente de resíduos da produção e do abate de pequenos ruminantes na cultura do milho. Artigo do Curso Bacharel em Biologia. Universidade Estadual Vale do Acaraú, Sobral. 26p.

Vilela HH, Rezende AV, Vieira PF, Andrade GA, Evangelista AR \& Almeida GBS (2008) Valor nutritivo de silagens de milho colhido em diversos estádios de maturação. Revista Brasileira de Zootecnia, 37:1192-1199.

Rev. Ceres, Viçosa, v. 64, n.3, p. 274-281, mai/jun, 2017 